\title{
Neurodegeneration and multiple sclerosis
}

\author{
Axel Petzold \\ June 26, 2017
}

\begin{abstract}
Neurodegeneration causes inexorable loss of neurons and function in both diseases and aging. Neurodegeneration damage produces a range of progressive disabilities from cognitive decline, behavioral, and mood disorders to problems with movement, coordination, and sensory dysfunction. Neurodegeneration is a major and growing public health issue which in its broadest sense embraces classical neurodegenerative disorders such as Alzheimer's disease and Parkinson's disease, as well as multiple sclerosis (MS), diabetes, acute brain injury among many other conditions. This chapter discusses the clinical and pathophysiological features of neurodegeneration in MS.
\end{abstract}

Keywords: Demyelinating disease, Multiple sclerosis, Neurodegeneration, Trans-synaptic axonal degeneration, Protein biomarker, Cerebrospinal fluid, Retina, Optical coherence tomography

\section{Contents}

1 Introduction 3

2 Historical Context 3

3 Pathological Features 6

3.1 Axonal Loss in Multiple Sclerosis . . . . . . . . . . . . . . 6

3.2 Concepts of Axonal Degeneration . . . . . . . . . . . 7 
4 The Patient 10

5 Clinical and Paraclinical Assessments 11

5.1 Clinical Scales . . . . . . . . . . . . . . . . . . . 11

5.2 Paraclinical Tests . . . . . . . . . . . . . . . . . . . 13

5.3 Acute Neurodegeneration in MS: Body Fluid Biomarkers . . 15

5.4 New Validated Atrophy Related Imaging Biomarkers for Neurodegeneration: Optical Coherence Tomography . . . . . 16

6 Outlook 17

7 Acknowledgements 17

$\begin{array}{ll}\text { References } & 19\end{array}$ 


\section{Introduction}

Neurodegeneration causes inexorable loss of neurons and function in both diseases and aging [126]. Neurodegeneration damage produces a range of progressive disabilities from cognitive decline, behavioral and mood disorders to problems with movement, co-ordination, and sensory dysfunction. Neurodegeneration is a major and growing public health issue which in its broadest sense embraces classical neurodegenerative disorders such as Alzheimer's disease and Parkinson's disease, as well as multiple sclerosis (MS), diabetes, acute brain injury among many other conditions. This chapter discusses the clinical and pathophysiological features of neurodegeneration in MS.

The historical context will be discussed first, because our understanding of MS pathology has been much influenced by demyelination and a concept of dissemination in time and space [32, 80]. Next, the classical pathological features of neurodegeneration in MS are reviewed in more detail [90]. Axonal loss will be placed centrally because of the important link to irreversible loss of function $[90,103,126]$. The resulting disability has a major impact on an individual patient's life [103]. Here limitations will be reviewed of those clinical and paraclinical assessments which were predominantly focused on demyelination and/or evidence for dissemination in time and space [32, 79]. It is against this backdrop that biomarkers for neurodegeneration will be presented [22]. The chapter closes with an outlook on how this knowledge may be applied to future treatment trials targeted at halting neurodegeneration in MS [103].

\section{Historical Context}

Most of the credited clinico-pathological descriptions of MS date back to the mid nineteenth century. The classical pathological features embrace inflammation, demyelination and gliosis [90, 95, 126].

Jean Marin Charcot, who pioneered the pathophysiological explanation of the symptoms observed in patients distinguished three steps in the pathology of MS, which he called la sclérose en plaques disseminée, la sclerose generalisée et la sclerose multiloculaire. First, astrocytic and microglial activation: "Ia multiplication des noyaux et l'hypertroplasie concomitante des fibres réticulées de la névroglie sont le fait initial". Sec- 
ond, neuro-axonal degeneration: "l'atrophie dégénerative des éléments nerveux est secondaire". The interested reader is referred to a wonderful historical account on axonal pathology for more details [66]. And third, astrogliosis: "la névroglie fait place au tissu fibrillaire". Ultimately, it was demyelination ("dépouillés de leur myéline" [21]) which became the key pathological feature of the disease, here depicted in a frequently cited sketch (Figure 1).

The cause for these features has remained enigmatic ever since James Dawson's dichotomization into "inflammatory" and "developmental" concepts [25] ${ }^{1}$.

Whilst pathologically succinct, the difficulty for the treating physician remains to recognize and communicate a diagnosis of MS to the patient. Historically, MS was recognised in the pre-antibiotic area where inflammatory diseases such as syphilis presented major public health issues. Separating one from the other was not always straightforward. Not surprisingly, given the multitude of symptoms and signs mimicking other diseases, MS was also considered a chameleon. In absence of a diagnostic test the clinical judgement cannot be substituted for. This notion is reflected in a series of diagnostic criteria, all more or less stating that the patient's symptoms and signs ought to be compatible with the characteristics of MS $[96,113,115]$. The careful and systematic, evidence-based approach on which these criteria rest, distilled a conceptual framework which may be phrased as "dissemination in time and space" [32].

Dissemination in time (DIT) and dissemination in space (DIS) are well suited to describe the occurrence of radiologically recognizable MS lesions in the brain and spinal cord [32].

It was precisely the absence of clear evidence for these characteristic features which made it so challenging to develop diagnostic criteria for primary progressive multiple sclerosis (PPMS) [138]. Later, Thompson and colleagues phrased this as: "Neither set of criteria is appropriate to PPMS, since the basic requirement of two discrete episodes of neurological dysfunction cannot by definition be fulfilled." [136]. The clinical corner stone of what emerged in International Panel diagnostic criteria was the documented clinical progression for more than one year [113].

Paradoxically, the first in vivo observation of axonal loss in MS was diffi-

\footnotetext{
${ }^{1}$ This dichotomisation remains a persistent intellectual concept with changing names such as "exogenous versus endogenous", "outside-in versus inside-out".
} 


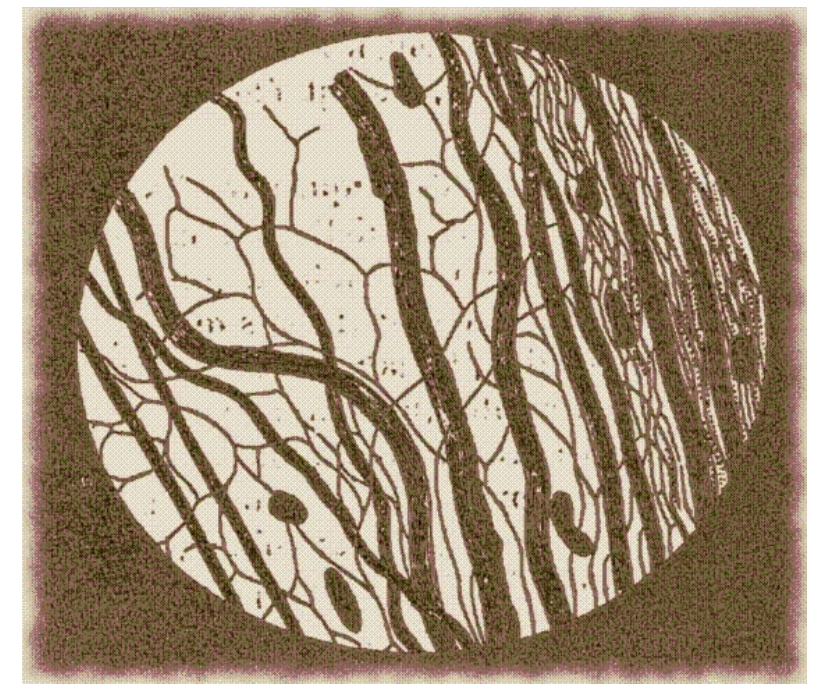

Figure 1: The figure shows the original sketch of an MS lesion from the landmark paper of Charcot [21]. The image depicts a fresh MS plaque colored with carmine. Charcot's text implies presence of axonal pathology based on morphological observations of diameter and continuity. His interpretation is careful as he does not exclude possible preparation- related artifacts. The original text reads as: "Elle représente une préparation frâche, provenant du centre d'une plaque scléreuse, colorié par le carmin et traité e par delacération. Au centre, vaisseau capillaire portant plusieurs noyaux. A droite et à gauche, cylindres d'axe, les uns volumineux, les autres d'un très-petit diamètre, tous dé pouillés de leur myéline. Le vaisseau capillaire et les cylindres d'axe étaient fortement colorés par le carmin. Les cylindres d'axe ont des bords parfaitement lisses, ne presentant aucune ramification. Dans l'intervalle des cylindres d'axe, membranes fibrilles de formation récente, à peu près parallèles les unes aux autres dans la partie droite de la préparation, formant à gauche et au centre, une sorte de réseau résultant, soit de l'enchevêment, soit de l'anastomose des fibrilles. Celles-ci se distinguent des cylindres d'axe, 1 par leur diamètre qui est beaucoup moindre; 2 par les ramifications qu'elles offrent dans leur trajet; 3 parce qu'elles ne se colorent pas par le carmin. - C á et et là , noyaux disséminés. Quelques-uns paraissant en connexion avec les fibrilles conjonctives; d'autres ayant pris une forme irre gulière, due à l'action de la solution ammoniacale du carmin."521]. 
cult to publish at all, according to anecdotal reports from the authors. Hoyt and colleagues had observed retinal nerve-fiber bundle defects in the eyes of patients with MS [50]. Much more frequently cited is the follow-up paper on this observation by Frisen et al. stating the presence of "insidious atrophy" of retinal nerve fibers in the eyes of patients with multiple sclerosis [36]. The second case reported by Frisen and Hoyt was a 15-year old student athlete with a clinical diagnosis of "multifocal demyelinating disease," but without any history of optic neuritis. One may speculate that one argument for rejection at the time might have been that multiple sclerosis was a demyelinating disease and the question was raised: why should there be at all atrophy of the non-myelinated axons in the eye of a patient who did not even suffer from optic neuritis?

Axonal loss was only some 24-years later firmly put on the MS research agenda by the American cell biologist Bruce Trapp and the Norwegian pathologist Lars Bo [140]. The conceptional change this influential pathological study had will be discussed in the next section.

\section{Pathological Features}

\subsection{Axonal Loss in Multiple Sclerosis}

In order to put the observation by Trapp et al into context, one needs to recall that axonal pathology may not be the most striking feature in the MS brain, but certainly is the one with the highest impact for the patient $[94,139,140,148,151]$. Historically, axonal loss in MS has been been associated with the "burnt-out" phase of the disease [41, 118]. Only with the wide availability of immunohistological techniques it was possible to demonstrate axonal pathology in active MS lesions [31]. There was extensive staining for amyloid precursor protein (APP) and the APP positive structures resembled transected axons. It was however the, three dimensional reconstruction of these axonal ovoids, using confocal microscopy, which conclusively demonstrated axonal transections within acute MS lesions [140]. Interestingly, an accumulation of neurofilament protein was observed in the so-called "end-bulbs." In vivo imaging of the development of axonal degeneration is available for experimental models [62, 93, 97].

In other words, the important new insight from this work was that a high number of transected axons were already present in acute lesions [31, 
140] and in patients with a short clinical course [140]. This data changed the earlier perception of axonal loss in MS [20,121].

The data from Trapp et al. is consistent with the concept that an important trigger for axonal loss are MS lesions [80]. But because disability continued to progress even after successful suppression of the inflammatory part of the disease, other aspects of axonal pathology were discussed [132]. Axons might be driven into a fatal energy deficit [90, 134, 141]. There is good evidence that mitochondrial pathology and sodium channel redistribution contribute to an "ATP penalty" [14, 19, 49, 81, 91, 150]. Axonal transport might be impaired [11, 67, 106, 127]. Next, there might be loss of trophic support or increase of inhibitory substances such as Nogo [52]. A barrier may result from astrogliosis. A low-grade inflammatory process might persist [48]. There is the problem of failure to remyelinate. There may be acceleration of physiological processes of agingrelated neurodegeneration. Endogenous capacities of repair might have their limits [48]. In sum, those factors causing axonal degeneration might eventually outnumber those which were protective [130].

It is worthwhile to remember some limitations, axonal injury remains a dynamic process and quantification of axonal loss in histological material might be complicated by tissue edema, the presence of inflammatory cells and the problem of establishing a relationship with the number of healthy axons. There is a crucial dependence on well-preserved tissue with limited capacities of the existing brain banks. Most post-mortem studies were biased to tissue from patients with long-standing disease duration and there is a lack of representative tissue from the clinically and therapeutically relevant early disease phase. Some early tissue might be available through biopsy, but again questions might be asked how representative such tissue really is if taken because the presentation was very atypical. Finally, there are shortcomings to the analytical methods, dyes, and antibodies used.

\subsection{Concepts of Axonal Degeneration}

Like axonal injury, axonal degeneration is also a dynamic process. Most recent insights come from experimental studies in mice on flurorescently labeled axons $[62,122]$. It may be opportune to go back in time and re-visit the first systematic description of axonal injury by Waller which gave rise to the eponym "Wallerian degeneration" [143]. 
In brief, Wallerian degeneration is a complex process which describes the degeneration of the distal axonal stump after axonal transection from the neuron. Wallerian degeneration begins with the enzymatic proteolysis of the axonal cytoskeleton [40]. Additionally, Wallerian degeneration affects also the sheathing glial cells, causes alterations in the adjacent blood-tissue barriers, and stimulates cells of macrophage lineage. From a mechanistic point of view Wallerian degeneration is of anterograde direction.

Wallerian degeneration has to be distinguished from dying back neuropathy, defined as the slow proximal spread of nerve fiber breakdown and ultimate apoptosis of the neuron [131]. The term dying back was introduced to describe the spatio-temporal pattern of central and peripheral nerve fiber pathology in degenerative diseases. Contemporary understanding is that axonal degeneration is defined by direction into anterograde and retrograde .

An important, mechanistic question to be asked is how the process of neurodegeneration can spread from a sick to a healthy neuron/axon? One attractive concept is trans-synpatic axonal degeneration [56, 58]. These authors used a non-invasive, utrarapid imaging technique, readily tolerated by patients, retinal optical coherence tomography (OCT) [57]. The study design was elegant and simple by focusing on neurodegeneration in the visual pathways. Following a stroke in the posterior visual pathways, dyingback neuropathy spread (trans-synaptic) from the second order neuron located in the lateral geniculate nucleus (LGN) to the axons (retinal nerve fiber layer, RNFL) of the first order neuron (retinal ganglion cell, RGC) [56, 58]. These studies have advanced the understanding of acquired axonal degeneration [26].

In addition to retrograde transynaptic axonal degeneration, there is evidence for anterograde trans-synaptic axonal degeneration from a postmortem study of the visual system of patients with multiple sclerosis [29].

Taken together, these data suggests a concept of bi-directional (transsynaptic) axonal degeneration [7] (Figure 2).

The attraction of this unified concept of bi-directional (transynaptic) axonal degeneration is that not only it is convenient to explaining how neurodegeneration spreads in MS, but more importantly it may contribute to opening a therapeutic window for future neuroprotective strategies in MS. The aim here will be to prevent the trans-synaptic part of the degenerative process and thereby at least limit the impairment for the patient. 


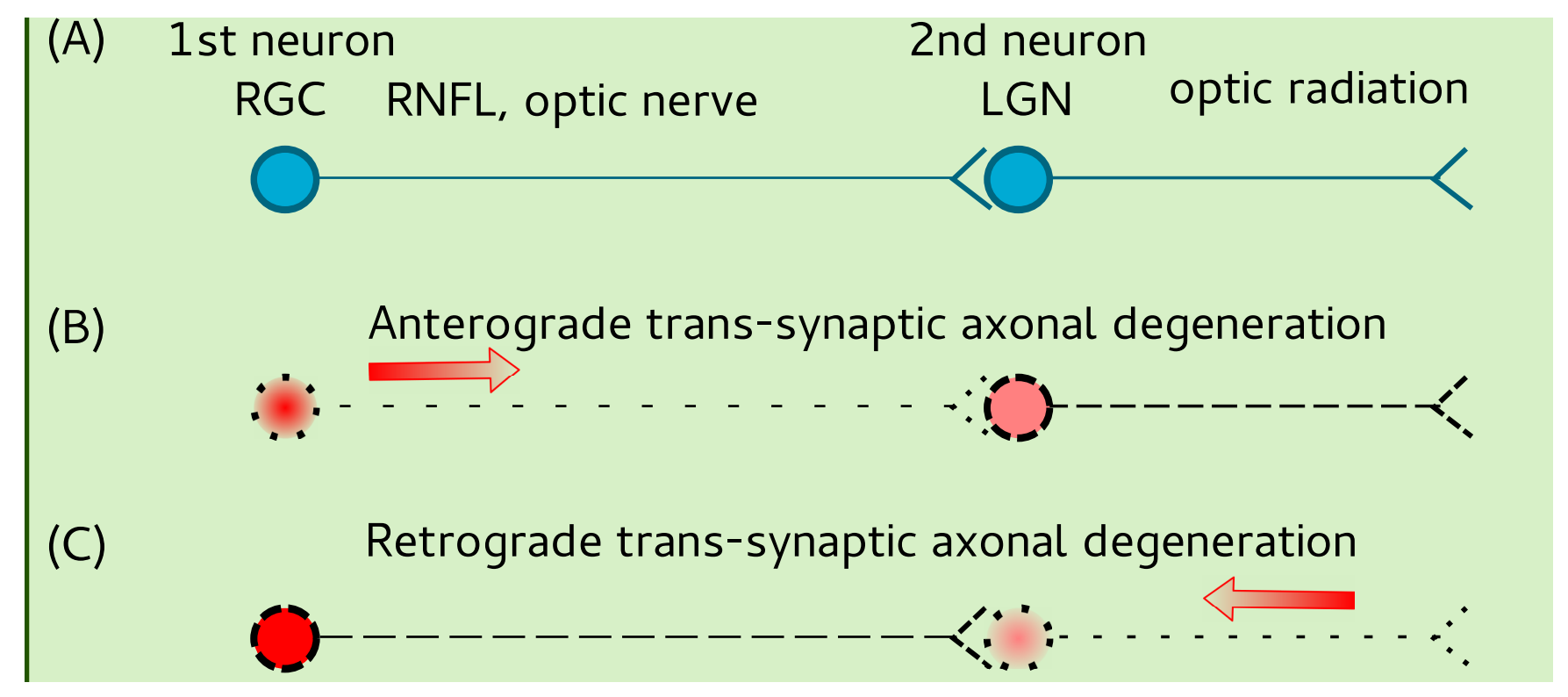

Figure 2: A simplified and uniform mechanistic concept of axonal degeneration. (A) The normal situation is here shown for the visual system. The first order neuron is represented by the retinal ganglion cell (RGC). The first axon is represented by the retinal nerve fiber layer (RNFL) which is named optic nerve after the axons passed through the lamina cribrosa. Here an axon is shown to synapse in the lateral geniculate nucleus (LGN) with the second order neuron. Next, the second neuron sends its axon through the optic radiations to the occipital cortex. (B) Anterograde axonal degeneration starts at the RGC/RNFL/optic nerve (e.g. with optic neuritis). Once anterograde axonal degeneration reaches the LGN, it continues as trans-synaptic anterograde axonal degeneration. (C) Retrograde axonal degeneration starts with axonal transections in the optic radiations (e.g. with eloquently placed white matter lesions). Once retrograde axonal degeneration reaches the LGN, the process continues as trans-synaptic retrograde axonal degeneration. Ultimately this leads to loss of retinal nerve fibers and apoptosis of the RGC. Longitudinally, the transynaptic part of this concept of bi-directional axonal degeneration will always have to occur with a time-lag. Understanding this timelag may potentially open a new therapeutic window for future neuroprotective strategies in MS 


\section{The Patient}

The use and definition of terms to describe a patients impairment, disability and handicap in this section were based on the recommendations of the system adopted by the World Health Organization (WHO).

Impairment describes the "loss or abnormality... of structure of function. Disability describes "a restriction or lack... of ability to perform an activity in the manner of within the range considered normal for a human being". Handicap describes "the disadvantage for an individual. . . that prevents or limits the performance of a role that is normal... for that individual". To be more specific, handicap represents the effects of impairments or disabilities in a wide social context and may be substantially influenced by the cultural background.

By definition (DIS and DIT [32]), a patient will suffer from MS related symptoms causing potentially reversible impairment in different parts of his/her body. From a patient's perception, gait and vision are the two most valuable functions [47]. Both gait and vision topped a list of 13 bodily functions during the early ( $<5$ years) and late ( $>15$ years) disease course. Importantly, early in the disease were patients were still ambulatory, gait was rated more valuable compared to visual function, but there was a crossover with long-disease duration. With the ever increasing use of visual communication channels (e.g., smart phones, tablets, social media), it can be anticipated that from a patients point of view the value and dependence on the visual system will continue to increase in the near future. This may be particularly true for those handicapped patients who crucially depend on the visual system for social interaction. Not surprisingly all of above is related to a patients Quality of Live [8].

Two questions are frequently asked by patients: "Will this happen again?" (relapse and "Will I end up in a wheel-chair?" (neurodegeneration). The first one may, with caution, be answered based on the momentary clinical and radiological disease activity. Addressing the second question is more challenging because of a relative lack of longitudinal data from wellvalidated outcome measures for neurodegeneration. 


\section{Clinical and Paraclinical Assessments}

"There are few neurological diseases in which the diagnosis depends so much upon the skill of the examiner in knowing what questions to ask and how to interpret the replies." [114]

\subsection{Clinical Scales}

Impairment or loss of function is quantified by clinical scales. The paradox between clinical examination and each clinical scale is that normal functioning is tested, but loss of function is quantified. Because of the potential of CNS regeneration and plasticity, the clinical appearance of disability is a dynamic process. This forms the basis on which MS patients had been classified [86]. A more recent approach separated an "active" from a "nonacitve" subtype based on clinical and MRI data [87].

A range of validated clinical scales is now in use. For MS the most widely applied scale is the extended disability status scale (EDSS) for multiple sclerosis developed by Kurtzke in 1983 [78]. The EDSS combines a disability status scale [76] with functional systems [77]. For a comprehensive up to date review of outcome measures in MS the reader is referred to van Munster and Uitdehaag [99].

Psychometry is tested by the Paced Auditory Serial Addition Test (PASAT) [42]. The National Adult Reading Test (NART) is used to give an estimate of the premorbid IQ [101]. Current intellectual function is assessed by the Advance Progressive Matrices, Set 1 (Ravens). Memory is assessed by recognition of words and faces [144]. The paired associated learning test estimates learning abilities. Attention is readily quantified by the speed of letter counting [149]. Tests of executive function include the Wisconsin Card Sorting Test (Nelson) and the Cambridge Neuropsychological Test Automated Battery (CANTAB) [101, 125]. Fatigue is commonly estimated by Krupp's Fatigue Rating Scale [68]. Anxiety and depression have been measured using the National Hospital anxiety and depression scale (HAD) measuring quality of life and measures for outcome of neuro-rehabilitation [137].

The timed walk test (TWT), 9 hole peg test (9HPT) and Paced Auditory Serial Addition Test (PASAT) have been combined mathematically to give the Multiple Sclerosis Functional Composite (MSFC) [24, 99]. The MSFC 
has the potential to provide a more reliable measure of changes of function in MS than the EDSS, which is non-linear and biased toward locomotion [9]. In addition, the MSFC may be perceived as a "melting pot" which permits to embrace other relevant clinical measures within a statistically valid concept. One potential extension of the MSFC may be low contrast letter acuity [6]. One advantage of such multidemensional measures relates to the potential to cover both disease activity and progression in MS [99].

A cross-sectional measure of disease severity in individual patients is provided by the global Multiple Sclerosis Severity Score (MSSS) [124]. The global MSSS is taken from a statistically constructed "look-up table." This table provides normally distributed disease severity scores for patients with an EDSS between 0 and 9.5 and a disease duration between 1 to 30 years.

Newer developments include patient-reported outcome measures (POM) [99]. A well established example for a POM is the MSIS-29 [46].

The advantages of clinical scales (and questionnaires) are that they may provide a more holistic view of an individual patients disability compared to paraclinical tests. But there are also limitations to be considered:

1. Psycho-physiological testing heavily depends on the patient's cooperation and motivation.

2. Biased to data from the system tested. This has been a frequently discussed limitation of the EDSS which is biased to the pyramidal system.

3. Learning effects. This is particularly challenging for testing cognition longitudinally.

4. Challenges of validation across cultural and language-barriers. This may impact on the use as an outcome measure in multi-center studies.

5. Multiple biological causes for poor performance. In MS this includes:

(a) Conduction block

(b) Demyelination

(c) Axonal loss 


\subsection{Paraclinical Tests}

"The technological advances that have contributed to a better understanding of the pathophysiology and pathogenesis of MS have resulted in a disturbing increase in the number of false diagnoses of MS based exclusively on the results of test procedures." [114]

Paraclinical tests are a double-edged sword, but do have their merits in experienced hands if used as an extension of the clinical reasoning. The four most frequently used paraclinical tests over the past 50-years comprise in alphabetical order: cerebrospinal fluid (CSF), computed tomography (CT), MRI and visual evoked potentials (VEP), acknowledging that MRI has become the sole paraclinical test of the 2010 revision of the McDonald criteria for RRMS [113]. A historical head-to-head comparison based on the earlier Poser criteria is presented in Table 1.

Of note, none of these studies investigated the relevance of any of these tests for axonal loss, which as pointed out earlier was not the main focus of MS research at the time.

Table 1: Paraclinical tests used in MS. For each test the diagnostic sensitivity of the respective study is presented alongside the author's main conclusions.

\begin{tabular}{llll}
\hline \hline Reference & Test & Sensitivity & Conclusion \\
\hline Polman et al. [112] & CSF & $72.2 \%$ & diagnostic classification \\
& CT $^{2}$ & $17.0 \%$ & differential diagnosis \\
& VEP & $62.0 \%$ & diagnostic classification \\
Beer et al [10] & CSF & $77 \%$ & best re-classification specificity \\
& MRI & $84 \%$ & highly sensitive, demonstrates DIS \\
Filippini et al [33] & VEP $37 \%$ & useful if MRI and CSF are not diagnostic \\
& CSF & & \\
& MRI $70 \%$ & most sensitive test \\
& VEP & & \\
\hline \hline
\end{tabular}

While sensitive for diagnostic purposes, the limitations of MRI to predict development disability were elegantly summarized by Kappos and col-

\footnotetext{
${ }^{2}$ This study also included a very small, $n=3$, number of MRI scans, BAER and SSER.
} 
leagues in a thoroughly conducted meta-analysis: "Neither the initial scan nor monthly scans over six months were predictive of change in the EDSS in the subsequent 12 months or 24 months. The mean of gadoliniumenhancing-lesion counts in the first six monthly scans was weakly predictive of EDSS change after 1 year (odds ratio $=1.34, p=0.082$ ) and 2 years (odds ratio $=1.65, p=0.049$ )" [60].

This meta-analysis demonstrates the difficulties in predicting accumulation of irreversible disability, which is related to neurodegeneration, based on a paraclinical test focused on inflammatory disease activity. In contrast, MRI data on CNS atrophy are much better correlated to sustained disability $[16,35]$. There is data on perfusion, functional MRI, high-field MRI, new sequences specifically addressing iron storage, double inversion recovery (DIR), and MR spectroscopy (MRS). For in-depth review of these and other MRI techniques the reader is referred to recent reviews on the issue $[39,61,123,145]$.

Likewise, for the CSF there is conflicting evidence on the relationship of CSF oligoclonal bands (OCBs) and disability [108]. There are some reports suggesting that the absence of OCBs in the CSF of patient with MS may be a good prognostic sign [30, 59, 69, 82, 98, 153]. Others did not find any prognostic value of either presence or absence of CSF OCBs $[51,65,84]$.

There may also be leverage using VEPs (and other evoked potentials) as a paraclinical test for neurodegeneration in MS [79].

It may be suggested to separate those paraclinical tests which permit detection of axonal loss (and neurodegeneration) in the acute phase from those which are superior for documenting axon loss after some time has elapsed. Tentatively, retinal OCT was added to this list as an emerging paraclinical test for retinal layer atrophy:

1. Early phase of ensuing axonal injury and loss:

- Biomarkers for acute axonal damage [27, 109, 133]

- Imaging markers for neuronal dysfunction and apoptosis [23, $100,146]$

2. Late phase of axonal loss having resulted in manifest atrophy:

- MRI atrophy markers $[83,147]$

- OCT $[18,110]$ 
- VEP and motor evoked potentials (MEP) $[64,79]$

\subsection{Acute Neurodegeneration in MS: Body Fluid Biomark- ers}

In MS disintegration of the axonal membrane causes release of biomarkers from injured axons and neurons in the surrounding extracellular fluid (ECF) [104]. These biomarkers diffuse from the brain ECF into the CSF and blood. Sampling from each of these body fluid compartments is possible with related advantages and disadvantages.

A review of the biomarker literature in MS shows that most early studies were cross-sectional and frequently of limited sample size $[4,12,13$, $28,71,109]$. This radically changed in the past two years. Pioneering studies relied on in-house developed immunoassays for the quantification of biomarkers. With availability of commercial tests for quantification of key biomarkers such as the neurofilament proteins from the blood the literature on the subject as increased exponentially [5, 27, 38].

Because of the essentially correlative nature of clinical biomarker investigations, only a snapshot in time is provided by cross-sectional studies. Not surprisingly, some studies find a clinical relevant correlation for a particular biomarker, while others do not. Some of these issues can be addressed by a meta-analysis. It will however be much more important to obtain high quality long-term data. Therefore, Table 2 summarizes blood biomarkers categorized to their cell-type-specificity. For an extended biomarker table and in-depth review on CSF biomarkers for Neurodegeneration see $[28,102,104]$.

Table 2: Blood biomarkers in MS and their cellular sources.

\begin{tabular}{lccccc}
\hline \hline $\begin{array}{l}\text { Blood } \\
\text { Biomarker }\end{array}$ & $\begin{array}{c}\text { Neuron } \\
\text { and Axon }\end{array}$ & $\begin{array}{c}\text { Astro- } \\
\text { cyte }\end{array}$ & $\begin{array}{c}\text { Micro- } \\
\text { glia }\end{array}$ & $\begin{array}{c}\text { Oligoden- } \\
\text { drocyte }\end{array}$ & $\begin{array}{c}\text { Other } \\
\text { cells }\end{array}$ \\
\hline $14-3-3 \gamma$ & + & + & + & + & + \\
Amyloid $\beta 42$ & + & & & & \\
Apo-E & + & + & + & & \\
FABPs & + & + & + & + & + \\
FFA & + & + & + & + & + \\
Ferritin & & & + & & + \\
GAP-43 & + & & & & + \\
Gelsolin & + & & & & + \\
GFAP & & + & & &
\end{tabular}




\begin{tabular}{|c|c|c|c|c|c|}
\hline HNE & + & + & + & + & + \\
\hline NSE & + & & & & + \\
\hline Neurofilaments & + & & & & \\
\hline S100B & & + & & + & + \\
\hline Tau & + & + & + & + & + \\
\hline UCHL-1 & + & & & & \\
\hline
\end{tabular}

The measurement of cell-type specific biomarkers indirectly permits to estimate the degree of damage to the respective cellular source. For example, an increase of blood neurofilament (Nf) levels gives indirect evidence for neuro-axonal damage. Neurofilaments have consistently found to be of prognostic value in MS $[3,17,27,44,70,74,75,88,89,92,107$, $111,135]$.

Importantly, there has been convincing analytical and experimental work to substantiate the hypothesis that $\mathrm{Nf}$ levels are related to neurodegeneration $[1,5,45,53,54,72,85,105,116,128,135]$. Tests are now commercially available with the most sensitive technology being Simoa [73].

\subsection{New Validated Atrophy Related Imaging Biomarkers for Neurodegeneration: Optical Coherence Tomog- raphy}

An emerging imaging technology for neurodegeneration in MS is retinal optical coherence tomography (OCT) [110]. The results of the early timedomain OCT meta-analysis have now been repeated for spectral-domain OCT. The results of the two meta-analyses were almost identical underlining the robustness of the method.

While it is well known that optic neuritis causes loss of the retinal nerve fiber layer [36], it only recently emerged that such atrophy can also be present in eyes not affected by optic neuritis [2, 15, 34, 37, 43, 55, 63, $110,117,119,120,129,142,152]$. Because retinal nerve fiber layer (RNFL) thickness also correlated with clinical scales and MRI measures there is a need to test the reliability and validity of OCT in a multi-center setting. 


\section{Outlook}

Taken together, neurodegeneration is an important feature of MS pathology because it is responsible for irreversible disability in patients. The dynamic nature of neurodegeneration poses challenges to the techniques used for monitoring. Some methods have their strengths in the acute phase; others only become reliable once neurodegeneration becomes manifest as atrophy. A holistic model combining the respective strength and weaknesses is presented in Figure 3.

This may be an opportune moment to end this chapter with an open question building on an analogy. In diabetes mellitus patients measure several times per day their blood glucose levels to optimise individual treatment. Additional paraclinical tests are used to closely monitor related organ damage with the aim to further guide patient management. How can we combine our respective expertise and methods to achieve a similar feat in MS?

\section{Acknowledgements}

The MS Center VUmc is partially funded by a program grant of the Dutch MS Research Foundation. The research of AP was supported by the $\mathrm{Na}-$ tional Institute for Health Research (NIHR) Biomedical Research Centre based at Moorfields Eye Hospital NHS Foundation Trust and UCL Institute of Ophthalmology. The views expressed are those of the author(s) and not necessarily those of the NHS, the NIHR or the Department of Health. 

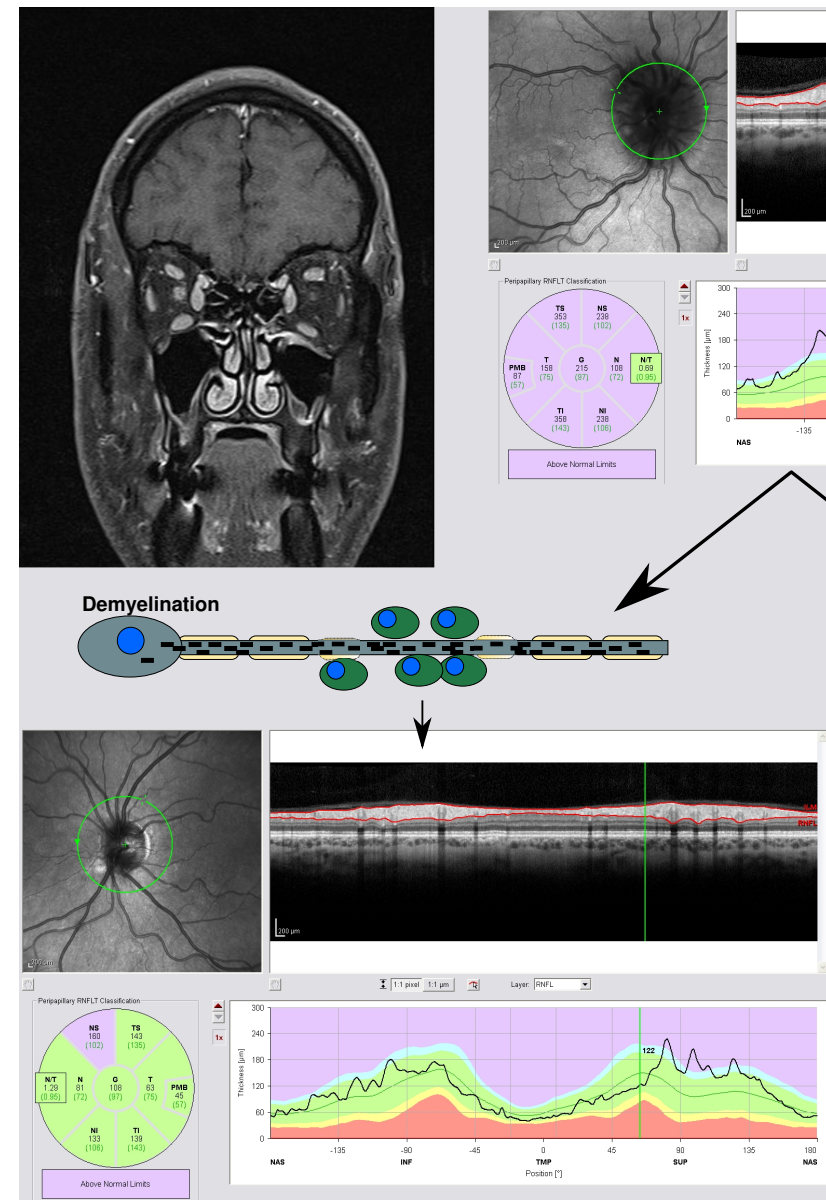

Figure 3: A holistic model combining the strength of biomarkers suited for diagnosis (whole brain and spinal cord MRI) of the acute phase of neurodegeneration (e.g. body fluid neurofilament levels) with those more reliable during the later phase of neurodegeneration related atrophy measures (retinal OCT). A fundamental problem of imaging techniques is that any inflammation related oedema in the acute phase will mask neurodegeneration-related atrophy. Likewise, body fluid biomarkers such as neurofilaments will predominanthsbe released from disintegrating axons/neurons during the acute phase and only to a smaller degree during the "burnt out phase". A logical combination of these two distinct methodological approaches would be to have them integrated in longitudinal studies on neurodegeneration in MS. 


\section{References}

[1] W.F. Abdo, B.P. van de Warrenburg, M. Munneke, W.J. van Geel, B.R. Bloem, H.P. Kremer, and M.M. Verbeek. "CSF analysis differentiates multiple-system atrophy from idiopathic late-onset cerebellar ataxia." Neurology 67 (2006), pp. 474-479.

[2] Philipp Albrecht, Ruth Fröhlich, Hans-Peter Hartung, Bernd C Kieseier, and Axel Methner. "Optical coherence tomography measures axonal loss in multiple sclerosis independently of optic neuritis." $J$ Neurol 254 (2007), pp. 1595-1596.

[3] Georgina Arrambide, Carmen Espejo, Herena Eixarch, Luisa M Villar, José C Alvarez-Cermeño, Carmen Picón, Jens Kuhle, Giulio Disanto, Ludwig Kappos, Jaume Sastre-Garriga, Deborah Pareto, Eva Simon, Manuel Comabella, Jordi Río, Carlos Nos, Carmen Tur, Joaquín Castilló, Angela Vidal-Jordana, Ingrid Galán, Maria J Arévalo, Cristina Auger, Alex Rovira, Xavier Montalban, and Mar Tintore. "Neurofilament light chain level is a weak risk factor for the development of MS." Neurology 87 (11 2016), pp. 1076-1084. ISSN: 1526-632X.

[4] Amer Awad, Bernhard Hemmer, Hans-Peter Hartung, Bernd Kieseier, Jeffrey L Bennett, and Olaf Stuve. "Analyses of cerebrospinal fluid in the diagnosis and monitoring of multiple sclerosis." J Neuroimmunol 219 (2010), pp. 1-7.

[5] Mehtap Bacioglu, Luis F Maia, Oliver Preische, Juliane Schelle, Anja Apel, Stephan A Kaeser, Manuel Schweighauser, Timo Eninger, Marius Lambert, Andrea Pilotto, Derya R Shimshek, Ulf Neumann, Philipp J Kahle, Matthias Staufenbiel, Manuela Neumann, Walter Maetzler, Jens Kuhle, and Mathias Jucker. "Neurofilament Light Chain in Blood and CSF as Marker of Disease Progression in Mouse Models and in Neurodegenerative Diseases." Neuron 91 (2 2016), pp. 494-496. ISSN: 1097-4199.

[6] L. J. Balcer, M. L. Baier, J. A. Cohen, M. F. Kooijmans, A. W. Sandrock, M. L. Nano-Schiavi, D. C. Pfohl, M. Mills, J. Bowen, C. Ford, F. R. Heidenreich, D. A. Jacobs, C. E. Markowitz, W. H. Stuart, G-S. Ying, S. L. Galetta, M. G. Maguire, and G. R. Cutter. "Contrast letter 
acuity as a visual component for the Multiple Sclerosis Functional Composite." Neurology 61 (2003), pp. 1367-1373.

[7] L. J. Balk, M. D. Steenwijk, P. Tewarie, M. Daams, J. Killestein, M. P. Wattjes, H. Vrenken, F. Barkhof, C. H. Polman, B M J. Uitdehaag, and A. Petzold. "Bidirectional trans-synaptic axonal degeneration in the visual pathway in multiple sclerosis." J Neurol Neurosurg Psychiatry 86 (2015), pp. 419-424.

[8] Lisanne J Balk, Danko Coric, Jenny A Nij Bijvank, Joep Killestein, Bernard Mj Uitdehaag, and Axel Petzold. "Retinal atrophy in relation to visual functioning and vision-related quality of life in patients with multiple sclerosis." Multiple sclerosis (Houndmills, Basingstoke, England) (2017), p. 1352458517708463. ISSN: 14770970.

[9] F Barkhof. "The clinico-radiological paradox in multiple sclerosis." Curr Opin Neurol 15 (2002), pp. 239-245.

[10] S. Beer, K. M. Rösler, and C. W. Hess. "Diagnostic value of paraclinical tests in multiple sclerosis: relative sensitivities and specificities for reclassification according to the Poser committee criteria." J Neurol Neurosurg Psychiatry 59 (1995), pp. 152-159.

[11] Robert van den Berg, Casper C Hoogenraad, and Rogier Q Hintzen. "Axonal transport deficits in multiple sclerosis: spiraling into the abyss." Acta neuropathologica 134 (1 2017), pp. 1-14. ISSN: 14320533.

[12] Thomas Berger and Markus Reindl. "Multiple sclerosis: disease biomarkers as indicated by pathophysiology." J Neurol Sci 259 (2007), pp. 21-26.

[13] B. Bielekova and R. Martin. "Development of biomarkers in multiple sclerosis." Brain 127 (2004), pp. 1463-1478.

[14] Joel A Black, Jia Newcombe, Bruce D Trapp, and Stephen G Waxman. "Sodium channel expression within chronic multiple sclerosis plaques." J Neuropathol Exp Neurol 66 (2007), pp. 828-837. 
[15] Markus Bock, Alexander U. Brandt, Jan Dörr, Helga Kraft, Nicholetta Weinges-Evers, Gunnar Gaede, Caspar F. Pfueller, Katja Herges, Helena Radbruch, Stephanie Ohlraun, Judith BellmannStrobl, Jörn Kuchenbecker, Frauke Zipp, and Friedemann Paul. "Patterns of retinal nerve fiber layer loss in multiple sclerosis patients with or without optic neuritis and glaucoma patients." Clin Neurol Neurosurg 112 (2010), pp. 647-652.

[16] U. Bonati, L. K. Fisniku, D. R. Altmann, M. C. Yiannakas, J. Furby, A. J. Thompson, D. H. Miller, and D. T. Chard. "Cervical cord and brain grey matter atrophy independently associate with long-term MS disability." J Neurol Neurosurg Psychiatry 82 (2011), pp. 471472.

[17] J. Brettschneider, A. Petzold, A. Junker, and H. Tumani. "Axonal damage markers in the cerebrospinal fluid of patients with clinically isolated syndrome improve predicting conversion to definite multiple sclerosis." Mult Scler 12 (2006), pp. 143-148.

[18] Josefine Britze, Gorm Pihl-Jensen, and Jette Lautrup Frederiksen. "Retinal ganglion cell analysis in multiple sclerosis and optic neuritis: a systematic review and meta-analysis." Journal of Neurology (2017). [epub ahead of print]. ISSN: 1432-1459.

[19] Melissa Cambron, Miguel DHaeseleer, Guy Laureys, Ralph Clinckers, Jan Debruyne, and Jacques De Keyser. "White-matter astrocytes, axonal energy metabolism, and axonal degeneration in multiple sclerosis." J Cereb Blood Flow Metab 32 (2012), pp. 413-424.

[20] M Charcot. "Histologie de la sclérose en plaques (I)." Gazette des hopitaux 14 (1868), pp. 554-555.

[21] M Charcot. "Histologie de la sclérose en plaques (II)." Gazette des hopitaux 14 (1868), pp. 557-558.

[22] Manuel Comabella and Xavier Montalban. "Body fluid biomarkers in multiple sclerosis." Lancet Neurol 13 (2014), pp. 113-126.

[23] Maria F Cordeiro, Eduardo M Normando, M Jorge Cardoso, Serge Miodragovic, Seham Jeylani, Benjamin M Davis, Li Guo, Sebastien Ourselin, Roger A'Hern, and Philip A Bloom. "Real-time imaging of single neuronal cell apoptosis in patients with glaucoma." Brain 140 (2017), pp. 1757-1767. 
[24] GR Cutter, ML Baier, RA Rudick, DL Cookfair, JS Fischer, J Petkau, K Syndulko, BG Weinshenker, JP Antel, C Confavreux, GW Ellison, $F$ Lublin, AE Miller, SM Rao, S Reingold, A Thompson, and E Willoughby. "Development of a multiple sclerosis functional composite as a clinical trial outcome measure." Brain 122 (1999), pp. 871882.

[25] J Dawson. "The histology of disseminated sclerosis." Trans Royal Soc Edin 50 (1916), pp. 517-740.

[26] Marc Dinkin. "Trans-synaptic Retrograde Degeneration in the Human Visual System: Slow, Silent, and Real." Current neurology and neuroscience reports 17 (2 2017), p. 16. ISSN: 1534-6293.

[27] Giulio Disanto, Christian Barro, Pascal Benkert, Yvonne Naegelin, Sabine Schädelin, Antonella Giardiello, Chiara Zecca, Kaj Blennow, Henrik Zetterberg, David Leppert, Ludwig Kappos, Claudio Gobbi, Jens Kuhle, and Swiss MS Cohort Study (SMSC) Group. "Serum neurofilament light: A biomarker of neuronal damage in multiple sclerosis." Annals of neurology (2017). ISSN: 1531-8249.

[28] Irena Dujmovic. "Cerebrospinal fluid and blood biomarkers of neuroaxonal damage in multiple sclerosis." Mult Scler Int (2011), pp. 767783.

[29] N. Evangelou. "Size-selective neuronal changes in the anterior optic pathways suggest a differential susceptibility to injury in multiple sclerosis." Brain 124 (2001), pp. 1813-1820.

[30] Gabriele Farina, Roberta Magliozzi, Marco Pitteri, Richard Reynolds, Stefania Rossi, Alberto Gajofatto, Maria Donata Benedetti, Francesco Facchiano, Salvatore Monaco, and Massimiliano Calabrese. "Increased cortical lesion load and intrathecal inflammation is associated with oligoclonal bands in multiple sclerosis patients: a combined CSF and MRI study." Journal of neuroinflammation 14 (1 2017), p. 40. ISSN: 1742-2094.

[31] B Ferguson, MK Matyszak, MM Esiri, and VH Perry. "Axonal damage in acute multiple sclerosis lesions." Brain 120 (1997), pp. 393399. 
[32] Massimo Filippi, Maria A Rocca, Olga Ciccarelli, Nicola De Stefano, Nikos Evangelou, Ludwig Kappos, Alex Rovira, Jaume Sastre-Garriga, Mar Tintorè, Jette L Frederiksen, Claudio Gasperini, Jacqueline Palace, Daniel S Reich, Brenda Banwell, Xavier Montalban, Frederik Barkhof, and MAGNIMS Study Group. "MRI criteria for the diagnosis of multiple sclerosis: MAGNIMS consensus guidelines." Lancet Neurol 15 (2016), pp. 292-303.

[33] G. Filippini, G. C. Comi, V. Cosi, L. Bevilacqua, M. Ferrarini, V. Martinelli, R. Bergamaschi, M. Filippi, A. Citterio, and L. DÍncerti. "Sensitivities and predictive values of paraclinical tests for diagnosing multiple sclerosis." J Neurol 241 (1994), pp. 132-137.

[34] Jennifer B Fisher, Dina A Jacobs, Clyde E Markowitz, Steven L Galetta, Nicholas J Volpe, M. Ligia Nano-Schiavi, Monika L Baier, Elliot M Frohman, Heather Winslow, Teresa C Frohman, Peter A Calabresi, Maureen G Maguire, Gary R Cutter, and Laura J Balcer. "Relation of visual function to retinal nerve fiber layer thickness in multiple sclerosis." Ophthalmology 113 (2006), pp. 324-332.

[35] Leonora K. Fisniku, Declan T. Chard, Jonathan S. Jackson, Valerie M. Anderson, Daniel R. Altmann, Katherine A. Miszkiel, Alan J. Thompson, and David H. Miller. "Gray matter atrophy is related to long-term disability in multiple sclerosis." Ann Neurol 64 (2008), pp. 247-254.

[36] L. Frisen and W. F. Hoyt. "Insidious atrophy of retinal nerve fibers in multiple sclerosis. Funduscopic identification in patients with and without visual complaints." Arch Ophthalmol 92 (1974), pp. 91-97.

[37] Elliot M Frohman, Michael G Dwyer, Teresa Frohman, Jennifer L Cox, Amber Salter, Benjamin M Greenberg, Sara Hussein, Amy Conger, Peter Calabresi, Laura J Balcer, and Robert Zivadinov. "Relationship of optic nerve and brain conventional and non-conventional MRI measures and retinal nerve fiber layer thickness, as assessed by OCT and GDx: a pilot study." J Neurol Sci 282 (2009), pp. 96105.

[38] Johanna Gaiottino, Niklas Norgren, Ruth Dobson, Joanne Topping, Ahuva Nissim, Andrea Malaspina, Jonathan P. Bestwick, Andreas U. Monsch, Axel Regeniter, Raija L. Lindberg, Ludwig Kappos, David 
Leppert, Axel Petzold, Gavin Giovannoni, and Jens Kuhle. "Increased neurofilament light chain blood levels in neurodegenerative neurological diseases." PLoS One 8 (2013), e75091.

[39] Achim Gass, Maria A. Rocca, Federica Agosta, Olga Ciccarelli, Declan Chard, Paola Valsasina, Jonathan C W. Brooks, Antje Bischof, Philipp Eisele, Ludwig Kappos, Frederik Barkhof, Massimo Filippi, et al. "MRI monitoring of pathological changes in the spinal cord in patients with multiple sclerosis." Lancet Neurol 14 (2015), pp. 443454.

[40] R George and JW Griffin. "Delayed macrophage responses and myelin clearance during Wallerian degeneration in the central nervous system: the dorsal radiculotomy model." Exp Neurol 129 (1994), pp. 225-236.

[41] JG Greenfield and LS King. "Observations on the histopathology of the cerebral lesions in desseminated sclerosis." Brain 59 (1936), pp. 445-458.

[42] DM Gronwall. "Paced auditory serial-addition task: a measure of recovery from concussion." Percept Mot Skills 44 (1977), pp. 367373.

[43] Fatih C Gundogan, Seref Demirkaya, and Gungor Sobaci. "Is optical coherence tomography really a new biomarker candidate in multiple sclerosis?-A structural and functional evaluation." Invest Ophthalmol Vis Sci 48 (2007), pp. 5773-5781.

[44] Martin Gunnarsson, Clas Malmeström, Markus Axelsson, Peter Sundström, Charlotte Dahle, Magnus Vrethem, Tomas Olsson, Fredrik Piehl, Niklas Norgren, Lars Rosengren, Anders Svenningsson, and Jan Lycke. "Axonal damage in relapsing multiple sclerosis is markedly reduced by natalizumab." Ann Neurol 69 (2011), pp. 83-89.

[45] Kelly Hares, Kevin Kemp, Elizabeth Gray, Neil Scolding, and Alastair Wilkins. "Neurofilament dot blot assays: novel means of assessing axon viability in culture." J Neurosci Methods 198 (2011), pp. 195-203. 
[46] Annie Hawton, Colin Green, Claire Telford, John Zajicek, and Dave Wright. "Using the Multiple Sclerosis Impact Scale to estimate health state utility values: mapping from the MSIS-29, version 2, to the EQ-5D and the SF-6D." Value Health 15 (2012), pp. 10841091.

[47] C. Heesen, J. Böhm, C. Reich, J. Kasper, M. Goebel, and S. M. Gold. "Patient perception of bodily functions in multiple sclerosis: gait and visual function are the most valuable." Mult Scler 14 (2008), pp. 988-991.

[48] Bernhard Hemmer, Martin Kerschensteiner, and Thomas Korn. "Role of the innate and adaptive immune responses in the course of multiple sclerosis." Lancet Neurol 14 (2015), pp. 406-419.

[49] Eva Herrero-Herranz, Luis A Pardo, Ralf Gold, and Ralf A Linker. "Pattern of axonal injury in murine myelin oligodendrocyte glycoprotein induced experimental autoimmune encephalomyelitis: implications for multiple sclerosis." Neurobiol Dis 30 (2008), pp. 162173.

[50] W. F. Hoyt, B. Schlicke, and R. J. Eckelhoff. "Fundoscopic appearance of a nerve-fibre-bundle defect." Br J Ophthalmol 56 (1972), pp. 577-583.

[51] Kerstin Imrell, Anne-Marie Landtblom, Jan Hillert, and Thomas Masterman. "Multiple sclerosis with and without CSF bands: clinically indistinguishable but immunogenetically distinct." Neurology 67 (2006), pp. 1062-1064.

[52] Benjamin V Ineichen, Sandra Kapitza, Christiane Bleul, Nicolas Good, Patricia S Plattner, Maryam S Seyedsadr, Julia Kaiser, Marc P Schneider, Björn Zörner, Roland Martin, Michael Linnebank, and Martin E Schwab. "Nogo-A antibodies enhance axonal repair and remyelination in neuro-inflammatory and demyelinating pathology." Acta neuropathologica (2017). ISSN: 1432-0533.

[53] Samuel J Jackson, David Baker, M. Louise Cuzner, and Lara T Diemel. "Cannabinoid-mediated neuroprotection following interferongamma treatment in a three-dimensional mouse brain aggregate cell culture." Eur J Neurosci 20 (2004), pp. 2267-2275. 
[54] SJ Jackson, LT Diemel, G Pryce, and D Baker. "Cannabinoids and neuroprotection in CNS inflammatory disease." J Neurol Sci 233 (2005), pp. 21-25.

[55] L. Jeanjean, G. Castelnovo, B. Carlander, M. Villain, F. Mura, G. Dupeyron, and P. Labauge. "[Retinal atrophy using optical coherence tomography (OCT) in 15 patients with multiple sclerosis and comparison with healthy subjects]." Rev Neurol (Paris) 164 (2008), pp. 927-934.

[56] P. Jindahra, A. Petrie, and G. T. Plant. "Retrograde trans-synaptic retinal ganglion cell loss identified by optical coherence tomography." Brain 132 (2009), pp. 628-634.

[57] Panitha Jindahra, Thomas R Hedges, Carlos E Mendoza-Santiesteban, and Gordon T Plant. "Optical coherence tomography of the retina: applications in neurology." Curr Opin Neurol 23 (2010), pp. 16-23.

[58] Panitha Jindahra, Aviva Petrie, and Gordon T. Plant. "The time course of retrograde trans-synaptic degeneration following occipital lobe damage in humans." Brain 135 (2012), pp. 534-541.

[59] F. G. Joseph, C. L. Hirst, T. P. Pickersgill, Y. Ben-Shlomo, N. P. Robertson, and N. J. Scolding. "CSF oligoclonal band status informs prognosis in multiple sclerosis: a case control study of 100 patients." J Neurol Neurosurg Psychiatry 80 (2009), pp. 292-296.

[60] L Kappos, D Moeri, et al. "Predictive value of gadolinium-enhanced magnetic resonance imaging for relapse rate and changes in disability or impairment in multiple sclerosis: a meta-analysis." Lancet 353 (1999), pp. 964-969.

[61] Ulrike W Kaunzner and Susan A Gauthier. "MRI in the assessment and monitoring of multiple sclerosis: an update on best practice." Therapeutic advances in neurological disorders 10 (6 2017), pp. 247-261. ISSN: 1756-2856.

[62] Martin Kerschensteiner, Martin E. Schwab, Jeff W. Lichtman, and Thomas Misgeld. "In vivo imaging of axonal degeneration and regeneration in the injured spinal cord." Nat Med 11 (2005), pp. 572577. 
[63] Alexander Klistorner, Hemamalini Arvind, Than Nguyen, Raymond Garrick, Mark Paine, Stuart Graham, Justin ODay, John Grigg, Francis Billson, and Con Yiannikas. "Axonal loss and myelin in early ON loss in postacute optic neuritis." Ann Neurol 64 (2008), pp. 325-331.

[64] Alexander Klistorner, Raymond Garrick, Michael H. Barnett, Stuart L. Graham, Hemamalini Arvind, Prema Sriram, and Con Yiannikas. "Axonal loss in non-optic neuritis eyes of patients with multiple sclerosis linked to delayed visual evoked potential." Neurology 80 (2013), pp. 242-245.

[65] M. Koch, D. Heersema, J. Mostert, A. Teelken, and J. De Keyser. "Cerebrospinal fluid oligoclonal bands and progression of disability in multiple sclerosis." Eur J Neurol 14 (2007), pp. 797-800.

[66] B. Kornek and H. Lassmann. "Axonal pathology in multiple sclerosis. A historical note." Brain Pathol 9 (1999), pp. 651-656.

[67] Mihaela Kreutzer, Frauke Seehusen, Robert Kreutzer, Kidsadagorn Pringproa, Maren Kummerfeld, Peter Claus, Ulrich Deschl, Arno Kalkul, Andreas Beineke, Wolfgang Baumgärtner, and Reiner UIrich. "Axonopathy is associated with complex axonal transport defects in a model of multiple sclerosis." Brain Pathol (2011).

[68] LB Krupp, NG LaRocca, J Muir-Nash, and AD Steinberg. "The fatigue severity scale Application to patients with multiple sclerosis and systemic lupus erythematosus." Arch Neurol 46 (1989), pp. 1121-1103.

[69] J. Kuhle, G. Disanto, R. Dobson, R. Adiutori, L. Bianchi, J. Topping, J. P. Bestwick, U-C. Meier, M. Marta, G Dalla Costa, T. Runia, E. Evdoshenko, N. Lazareva, E. Thouvenot, P. laffaldano, V. Direnzo, M. Khademi, F. Piehl, M. Comabella, M. Sombekke, J. Killestein, H. Hegen, S. Rauch, S. DÁlfonso, J. C. Alvarez-Cermeño, P. Kleinová, D. Horáková, R. Roesler, F. Lauda, S. Llufriu, T. Avsar, U. Uygunoglu, A. Altintas, S. Saip, T. Menge, C. Rajda, R. Bergamaschi, N. Moll, M. Khalil, R. Marignier, I. Dujmovic, H. Larsson, C. Malmestrom, E. Scarpini, C. Fenoglio, S. Wergeland, A. Laroni, V. Annibali, S. Romano, A. D. Martínez, A. Carra, M. Salvetti, A. Uccelli, Ø. Torkildsen, K. M. Myhr, D. Galimberti, K. Rejdak, J. Lycke, J. L. Frederiksen, J. Drulovic, C. Confavreux, D. Brassat, C. Enzinger, S. 
Fuchs, I. Bosca, J. Pelletier, C. Picard, E. Colombo, D. Franciotta, T. Derfuss, RIp Lindberg, Ö. Yaldizli, L. Vécsei, B. C. Kieseier, H. P. Hartung, P. Villoslada, A. Siva, A. Saiz, H. Tumani, E. Havrdová, L. M. Villar, M. Leone, N. Barizzone, F. Deisenhammer, C. Teunissen, X. Montalban, M. Tintoré, T. Olsson, M. Trojano, S. Lehmann, G. Castelnovo, S. Lapin, R. Hintzen, L. Kappos, R. Furlan, V. Martinelli, G. Comi, S. V. Ramagopalan, and G. Giovannoni. "Conversion from clinically isolated syndrome to multiple sclerosis: A large multicentre study." Mult Scler 21 (2015), pp. 1013-1024.

[70] J. Kuhle, D. Leppert, A. Petzold, A. Regeniter, C. Schindler, M. Mehling, D. C. Anthony, L. Kappos, and R. L P Lindberg. "Neurofilament heavy chain in CSF correlates with relapses and disability in multiple sclerosis." Neurology 76 (2011), pp. 1206-1213.

[71] J. Kuhle and A Petzold. "What makes a prognostic biomarker in CNS diseases: strategies for targeted biomarker discovery? Part 2: chronic progressive and relapsing diseases." Expert Opinion on Medical Diagnostics 5 (2011), pp. 393-410.

[72] J Kuhle, A Regeniter, D Leppert, M Mehling, L Kappos, RLP Lindberg, and A Petzold. "A highly sensitive electrochemiluminescence immunoassay for the neurofilament heavy chain protein." J Neuroimmonology 220 (2010), pp. 114-119.

[73] Jens Kuhle, Christian Barro, Ulf Andreasson, Tobias Derfuss, Raija Lindberg, Åsa Sandelius, Victor Liman, Niklas Norgren, Kaj Blennow, and Henrik Zetterberg. "Comparison of three analytical platforms for quantification of the neurofilament light chain in blood samples: ELISA, electrochemiluminescence immunoassay and Simoa." Clinical chemistry and laboratory medicine 54 (10 2016), pp. 16551661. ISSN: $1437-4331$.

[74] Jens Kuhle, Christian Barro, Giulio Disanto, Amandine Mathias, Charlotte Soneson, Guillaume Bonnier, Özguer Yaldizli, Axel Regeniter, Tobias Derfuss, Mathieu Canales, Myriam Schluep, Renaud Du Pasquier, Gunnar Krueger, and Cristina Granziera. "Serum neurofilament light chain in early relapsing remitting MS is increased and correlates with CSF levels and with MRI measures of disease severity." Multiple sclerosis (Houndmills, Basingstoke, England) 22 (12 2016), pp. 1550-1559. ISSN: 1477-0970. 
[75] Jens Kuhle, Bardia Nourbakhsh, Donna Grant, Steve Morant, Christian Barro, Özgür Yaldizli, Daniel Pelletier, Gavin Giovannoni, Emmanuelle Waubant, and Sharmilee Gnanapavan. "Serum neurofilament is associated with progression of brain atrophy and disability in early MS." Neurology 88 (9 2017), pp. 826-831. ISSN: 1526$632 X$.

[76] JF Kurtzke. "A new scale for evaluating disability in multiple sclerosis." Neurology 5 (1955), pp. 580-583.

[77] JF Kurtzke. "Natural history and clinical outcome measures for multiple sclerosis studies. Why at the present time does EDSS scale remain a preferred outcome measure to evaluate disease evolution?" Neurol Sci 21 (2000), pp. 339-341.

[78] JF Kurtzke. "Rating neurological impairment in multiple sclerosis: an expanded disability status scale (EDSS)." Neurology 33 (1983), pp. 1444-1452.

[79] Agustina M Lascano, Patrice H Lalive, Martin Hardmeier, Peter Fuhr, and Margitta Seeck. "Clinical evoked potentials in neurology: a review of techniques and indications." Journal of neurology, neurosurgery, and psychiatry (2017). ISSN: 1468-330X.

[80] Hans Lassmann and Monika Bradl. "Multiple sclerosis: experimental models and reality." Acta neuropathologica 133 (2 2017), pp. 223-244. ISSN: 1432-0533.

[81] G. Lazzarino, A. M. Amorini, M. J. Eikelenboom, J. Killestein, A. Belli, V. Di Pietro, B. Tavazzi, F. Barkhof, C. H. Polman, B. M J Uitdehaag, and A. Petzold. "Cerebrospinal fluid ATP metabolites in multiple sclerosis." Mult Scler 16 (2010), pp. 549-554.

[82] J. Lechner-Scott, B. Spencer, T. de Malmanche, J. Attia, M. Fitzgerald, M. Trojano, F. Grandaison, J. Antonio C Gomez, G. Izquierdo, P. Duquette, M. Girard, P. Grammond, C. Oreja-Guevara, R. Hupperts, R. Bergamaschi, C. Boz, G. Giuliani, V van Pesch, G. Iuliano, M. Fiol, E. Cristiano, F. Verheul, M Laura Saladino, M. Slee, M. Barnett, N. Deri, S. Fletcher, N. Vella, C. Shaw, J. Herbert, F. Moore, T. Petkovska-Boskova, V. Jokubatis, and H. Butzkueven. "The frequency of CSF oligoclonal banding in multiple sclerosis increases with latitude." Mult Scler (2011). 
[83] Letizia Leocani, Maria A Rocca, and Giancarlo Comi. "MRI and neurophysiological measures to predict course, disability and treatment response in multiple sclerosis." Curr Opin Neurol 29 (2016), pp. 243-253.

[84] Pedro Lourenco, Afsaneh Shirani, Jameelah Saeedi, Joel Oger, William E Schreiber, and Helen Tremlett. "Oligoclonal bands and cerebrospinal fluid markers in multiple sclerosis: associations with disease course and progression." Multiple sclerosis (Houndmills, Basingstoke, England) 19 (5 2013), pp. 577-584. ISSN: 1477-0970.

[85] Ching-Hua Lu, Bernadett Kalmar, Andrea Malaspina, Linda Greensmith, and Axel Petzold. "A method to solubilise protein aggregates for immunoassay quantification which overcomes the neurofilament "hook" effect." J Neurosci Methods 195 (2011), pp. 143-150.

[86] FD Lublin and SC Reingold. "Defining the clinical course of multiple sclerosis: results of an international survey National Multiple Sclerosis Society (USA) Advisory Committee on Clinical Trials of New Agents in Multiple Sclerosis." Neurology 46 (1996), pp. 907-911.

[87] Fred D. Lublin, Stephen C. Reingold, Jeffrey A. Cohen, Gary R. Cutter, Per Soelberg Sørensen, Alan J. Thompson, Jerry S. Wolinsky, Laura J. Balcer, Brenda Banwell, Frederik Barkhof, Bruce Bebo Jr, Peter A. Calabresi, Michel Clanet, Giancarlo Comi, Robert J. Fox, Mark S. Freedman, Andrew D. Goodman, Matilde Inglese, Ludwig Kappos, Bernd C. Kieseier, John A. Lincoln, Catherine Lubetzki, Aaron E. Miller, Xavier Montalban, Paul W. OĆonnor, John Petkau, Carlo Pozzilli, Richard A. Rudick, Maria Pia Sormani, Olaf Stüve, Emmanuelle Waubant, and Chris $\mathrm{H}$. Polman. "Defining the clinical course of multiple sclerosis: The 2013 revisions." Neurology 83 (2014), pp. 278-286.

[88] J. N. Lycke, J. E. Karlsson, O. Andersen, and L. E. Rosengren. "Neurofilament protein in cerebrospinal fluid: a potential marker of activity in multiple sclerosis." J Neurol Neurosurg Psychiatry 64 (1998), pp. 402-404.

[89] J Lycke, O Andersen, and L Rosengren. "Neurofilament in cerebrospinal fluid: a potential marker of activity in multiple sclerosis." Eur J Neurol 3 (1996), p. 100. 
[90] Don H. Mahad, Bruce D. Trapp, and Hans Lassmann. "Pathological mechanisms in progressive multiple sclerosis." Lancet Neurol 14 (2015), pp. 183-193.

[91] Don J Mahad, Iryna Ziabreva, Graham Campbell, Nichola Lax, Katherine White, Peter S Hanson, Hans Lassmann, and Douglass M Turnbull. "Mitochondrial changes within axons in multiple sclerosis." Brain 132 (2009), pp. 1161-1174.

[92] C. Malmeström, S. Haghighi, L. Rosengren, O. Andersen, and J. Lycke. "Neurofilament light protein and glial fibrillary acidic protein as biological markers in MS." Neurology 61 (2003), pp. 1720-1725.

[93] Petar Marinkovic, Miriam S. Reuter, Monika S. Brill, Leanne Godinho, Martin Kerschensteiner, and Thomas Misgeld. "Axonal transport deficits and degeneration can evolve independently in mouse models of amyotrophic lateral sclerosis." Proc Natl Acad Sci U S A 109 (2012), pp. 4296-4301.

[94] WI McDonald. "Relapse, Remission, and Progression in Multiple Sclerosis." N Engl J Med 343 (2000), pp. 1486-1487.

[95] WI McDonald, DH Miller, and D Barnes. "The pathological evolution of multiple sclerosis." Neuropathol Appl Neurobiol 18 (1992), pp. 319-334.

[96] WI McDonald, A Compston, G Edan, et al. "Recommended diagnostic criteria for multiple sclerosis: guidelines from the International Panel on the diagnosis of multiple sclerosis." Ann Neurol 50 (2001), pp. 121-127.

[97] Thomas Misgeld and Martin Kerschensteiner. "In vivo imaging of the diseased nervous system." Nat Rev Neurosci 7 (2006), pp. 449-463.

[98] D. Moulin, D. W. Paty, and G. C. Ebers. "The predictive value of cerebrospinal fluid electrophoresis in ossible multiple sclerosis." Brain 106 ( Pt 4) (1983), pp. 809-816.

[99] Caspar E P van Munster and Bernard M J Uitdehaag. "Outcome Measures in Clinical Trials for Multiple Sclerosis." CNS drugs (2017). [Epub ahead of print]. ISSN: 1179-1934. 
[100] P. A. Narayana, T. J. Doyle, D. Lai, and J. S. Wolinsky. "Serial proton magnetic resonance spectroscopic imaging, contrast-enhanced magnetic resonance imaging, and quantitative lesion volumetry in multiple sclerosis." Ann Neurol 43 (1998), pp. 56-71.

[101] HE Nelson, ed. National Adult reading test: Manual. Windsor: NFER-Nelson, 1982.

[102] Bob Olsson, Ronald Lautner, Ulf Andreasson, Annika Öhrfelt, Erik Portelius, Maria Bjerke, Mikko Hölttä, Christoffer Rosén, Caroline Olsson, Gabrielle Strobel, et al. "CSF and blood biomarkers for the diagnosis of Alzheimerś disease: a systematic review and metaanalysis." The Lancet Neurology 15 (2016), pp. 673-684.

[103] Daniel Ontaneda, Alan J Thompson, Robert J Fox, and Jeffrey A Cohen. "Progressive multiple sclerosis: prospects for disease therapy, repair, and restoration of function." Lancet (London, England) 389 (10076 2017), pp. 1357-1366. ISSN: 1474-547X.

[104] A Petzold. "Progressive Multiple Sclerosis." Ed. by A. Wilkins. Springer-Verlag, 2013. Chap. Biomarkers of Disease Progression, pp. 115-146.

[105] A. Petzold, D. Baker, G. Pryce, G. Keir, E. J. Thompson, and G. Giovannoni. "Quantification of neurodegeneration by measurement of brain-specific proteins." J Neuroimmunol 138 (2003), pp. 45-48.

[106] A. Petzold, D. Gveric, M. Groves, K. Schmierer, D. Grant, M. Chapman, G. Keir, L. Cuzner, and E. J. Thompson. "Phosphorylation and compactness of neurofilaments in multiple sclerosis: indicators of axonal pathology." Exp Neurol 213 (2008), pp. 326-335.

[107] A Petzold, K Rejdak, and GT Plant. "Axonal degeneration and inflammation in acute optic neuritis." J Neurol Neurosurg Psychiatry 75 (2004), pp. 1178-1180.

[108] Axel Petzold. "Intrathecal oligoclonal IgG synthesis in multiple sclerosis." J Neuroimmunol 262 (2013), pp. 1-10.

[109] Axel Petzold. "Neurofilament phosphoforms: surrogate markers for axonal injury, degeneration and loss." J Neurol Sci 233 (2005), pp. 183-198. 
[110] Axel Petzold, Johannes F de Boer, Sven Schippling, Patrik Vermersch, Randy Kardon, Ari Green, Peter A Calabresi, and Chris Polman. "Optical coherence tomography in multiple sclerosis: a systematic review and meta-analysis." Lancet Neurol 9 (2010), pp. 921-932.

[111] Axel Petzold, Tjeerd Mondria, Jens Kuhle, Maria A Rocca, Jan Cornelissen, Peter Te Boekhorst, Bob Lowenberg, Gavin Giovannoni, Massimo Filippi, Ludwig Kappos, and Rogier Hintzen. "Evidence for acute neurotoxicity after chemotherapy." Ann Neurol 68 (2010), pp. 806-815.

[112] C. H. Polman, J. C. Koetsier, and E. C. Wolters. "Multiple sclerosis: incorporation of results of laboratory techniques in the diagnosis." Clin Neurol Neurosurg 87 (1985), pp. 187-192.

[113] Chris H. Polman, Stephen C. Reingold, Brenda Banwell, Michel Clanet, Jeffrey A. Cohen, Massimo Filippi, Kazuo Fujihara, Eva Havrdova, Michael Hutchinson, Ludwig Kappos, Fred D. Lublin, Xavier Montalban, Paul OĆonnor, Magnhild Sandberg-Wollheim, Alan J. Thompson, Emmanuelle Waubant, Brian Weinshenker, and Jerry S. Wolinsky. "Diagnostic criteria for multiple sclerosis: 2010 revisions to the McDonald criteria." Ann Neurol 69 (2011), pp. 292302.

[114] C. M. Poser. "The unfortunate triumph of mechanodiagnosis in multiple sclerosis: a clinicianś lament." Clin Neurol Neurosurg 94 Suppl (1992), S139-S142.

[115] C. M. Poser, D. W. Paty, L. Scheinberg, W. I. McDonald, F. A. Davis, G. C. Ebers, K. P. Johnson, W. A. Sibley, D. H. Silberberg, and W. W. Tourtellotte. "New diagnostic criteria for multiple sclerosis: guidelines for research protocols." Ann Neurol 13 (1983), pp. 227231.

[116] G Pryce, Z Ahmed, DJ Hankey, et al. "Cannabinoids inhibit neurodegeneration in models of multiple sclerosis." Brain 127 (2003), pp. 2191-2202.

[117] M. Pulicken, E. Gordon-Lipkin, L. J. Balcer, E. Frohman, G. Cutter, and P. A. Calabresi. "Optical coherence tomography and disease subtype in multiple sclerosis." Neurology 69 (2007), pp. 20852092. 
[118] TJ Putnam. "Studies in Multiple Sclerosis VII Similarities between some forms of "Encephalomyelitis" and Multiple Sclerosis." Arch Neurol Psychiatry (1935), pp. 1289-1308.

[119] Amanda Quelly, Han Cheng, Michal Laron, Jade S Schiffman, and Rosa A Tang. "Comparison of Optical Coherence Tomography and Scanning Laser Polarimetry Measurements in Patients with Multiple Sclerosis." Optom Vis Sci 87 (2010), p. 576.

[120] J. N. Ratchford, M. E. Quigg, A. Conger, T. Frohman, E. Frohman, L. J. Balcer, P. A. Calabresi, and D. A. Kerr. "Optical coherence tomography helps differentiate neuromyelitis optica and MS optic neuropathies." Neurology 73 (2009), pp. 302-308.

[121] E Rindfleisch. "Histologisches Detail zur grauen Degeneration von Gehirn und RÃ $\frac{1}{4}$ ckenmark." Arch Pathol Anat Physiol Klin Med (Virchow) 26 (1863), pp. 474-483.

[122] Elisa Romanelli, Catherine D. Sorbara, Ivana NikiÄ, Athanasios Dagkalis, Thomas Misgeld, and Martin Kerschensteiner. "Cellular, subcellular and functional in vivo labeling of the spinal cord using vital dyes." Nat Protoc 8 (2013), pp. 481-490.

[123] Àlex Rovira, Mike $P$ Wattjes, Mar Tintoré, Carmen Tur, Tarek A Yousry, Maria P Sormani, Nicola De Stefano, Massimo Filippi, Cristina Auger, Maria A Rocca, Frederik Barkhof, Franz Fazekas, Ludwig Kappos, Chris Polman, David Miller, Xavier Montalban, and MAGNIMS study group. "Evidence-based guidelines: MAGNIMS consensus guidelines on the use of MRI in multiple sclerosis-clinical implementation in the diagnostic process." Nat Rev Neurol 11 (2015), pp. 471-482.

[124] RHSR Roxburgh, SR Seaman, T Masterman, AE Hensiek, SJ Sawcer, $S$ Vukusic, et al. "Multiple Sclerosis Severity Score. Using disability and disease duration to rate disease severity." Neurology 64 (2005), pp. 1144-1151.

[125] BJ Sahakian and MA Owen. "Computerized assessment in neuropsychiatry using CANTAB." discussion paper. Vol. 85. 1992, pp. 399-402. 
[126] Hannah E Salapa, Sangmin Lee, Yoojin Shin, and Michael C Levin. "Contribution of the Degeneration of the Neuro-Axonal Unit to the Pathogenesis of Multiple Sclerosis." Brain sciences 7 (6 2017). ISSN: 2076-3425.

[127] Lucas Schirmer, Doron Merkler, Fatima B. KÃ Inig, Wolfgang BrÃ 14ck, and Christine Stadelmann. "Neuroaxonal regeneration is more pronounced in early multiple sclerosis than in traumatic brain injury lesions." Brain Pathol 23 (2013), pp. 2-12.

[128] G Shaw, C Yang, R Ellis, K Anderson, et al. "Hyperphosphorylated neurofilament NF-H is a serum biomarker for axonal injury." Biochem Biophys Res Comm 336 (2005), pp. 1268-1277.

[129] Malgorzata Siger, Krzysztof Dziegielewski, Lukasz Jasek, Marek Bieniek, Agnieszka Nicpan, Jerzy Nawrocki, and Krzysztof Selmaj. "Optical coherence tomography in multiple sclerosis: thickness of the retinal nerve fiber layer as a potential measure of axonal loss and brain atrophy." J Neurol 255 (2008), pp. 1555-1560.

[130] Mikael Simons, Thomas Misgeld, and Martin Kerschensteiner. "A unified cell biological perspective on axon-myelin injury." J Cell Biol 206 (2014), pp. 335-345.

[131] PS Spencer and HH Schaumburg. "Ultrastructural studies of the dying-back process IV Differential vulnerability of PNS and CNS fibers in experimental central-peripheral distal axonopathies." $J$ Neuropathol Exp Neurol 36 (1977), pp. 300-320.

[132] Christine Stadelmann. "Multiple sclerosis as a neurodegenerative disease: pathology, mechanisms and therapeutic implications." Curr Opin Neurol 24 (2011), pp. 224-229.

[133] Martin Stangel, Sten Fredrikson, Edgar Meinl, Axel Petzold, Olaf StÃ $14 v e$, and Hayrettin Tumani. "The utility of cerebrospinal fluid analysis in patients with multiple sclerosis." Nat Rev Neurol 9 (2013), pp. 267-276.

[134] Kimmy G Su, Gary Banker, Dennis Bourdette, and Michael Forte. "Axonal degeneration in multiple sclerosis: the mitochondrial hypothesis." Curr Neurol Neurosci Rep 9 (2009), pp. 411-417. 
[135] C. E. Teunissen, E. lacobaeus, M. Khademi, L. Brundin, N. Norgren, M. J A Koel-Simmelink, M. Schepens, F. Bouwman, H. A M Twaalfhoven, H. J. Blom, C. Jakobs, and C. D. Dijkstra. "Combination of CSF N-acetylaspartate and neurofilaments in multiple sclerosis." Neurology 72 (2009), pp. 1322-1329.

[136] A. J. Thompson, X. Montalban, F. Barkhof, B. Brochet, M. Filippi, D. H. Miller, C. H. Polman, V. L. Stevenson, and W. I. McDonald. "Diagnostic criteria for primary progressive multiple sclerosis: a position paper." Ann Neurol 47 (2000), pp. 831-835.

[137] AJ Thompson. "Multiple sclerosis: Rehabilitation measures." Seminars Neurology 18 (1998), pp. 397-403.

[138] AJ Thompson, CH Polman, DH Miller, WI McDonald, B Brochet, $M$ Filippi $X$ andM Montalban, and J De Sa. "Primary progressive multiple sclerosis." Brain 120 (1997), pp. 1085-1096.

[139] BD Trapp, RM Ransohoff, E Fisher, and RA Rudick. "Neurodegeneration in multiple sclerosis, relationship to neurological disability." Neuroscientist 5 (1999), pp. 48-57.

[140] BD Trapp, JP Peterson, et al. "Axonal transection in the lesions of multiple sclerosis." N Eng J Med 338 (1998), pp. 278-285.

[141] Bruce D Trapp and Peter K Stys. "Virtual hypoxia and chronic necrosis of demyelinated axons in multiple sclerosis." Lancet Neurol 8 (2009), pp. 280-291.

[142] S. Anand Trip, Patricio G Schlottmann, Stephen J Jones, Daniel R Altmann, David F Garway-Heath, Alan J Thompson, Gordon T Plant, and David $\mathrm{H}$ Miller. "Retinal nerve fiber layer axonal loss and visual dysfunction in optic neuritis." Ann Neurol 58 (2005), pp. 383-391.

[143] A Waller. "Experiments on the section of glossopharyngeal and hypoglossal nerves of the frog and observations of the alternatives produced thereby in the structure of their primitive fibres." Philos Trans R Soc London 140 (1850), pp. 423-429.

[144] EK Warrington, ed. Recognition memory tests. NFER Nelson: Windsor, 1984. 
[145] Mike P. Wattjes and Frederik Barkhof. "High field MRI in the diagnosis of multiple sclerosis: high field-high yield?" Neuroradiology 51 (2009), pp. 279-292.

[146] Mike P. Wattjes, Michael Harzheim, Götz G. Lutterbey, Manuela Bogdanow, Stephan Schmidt, Hans H. Schild, and Frank TrÃber. "Prognostic value of high-field proton magnetic resonance spectroscopy in patients presenting with clinically isolated syndromes suggestive of multiple sclerosis." Neuroradiology 50 (2008), pp. 123129.

[147] MP Wattjes, MD Steenwijk, and M Stangel. "MRI in the Diagnosis and Monitoring of Multiple Sclerosis: An Update." Clin Neuroradiol 25 Suppl 2 (2015), pp. 157-165.

[148] SG Waxman. "Demyelinating Diseases - new pathological insights, new therapeutic targets." N Eng J Med 338 (1998), pp. 323325.

[149] JR Willison, DJ Thomas, GH du Boulay, et al. "Effect of high haematocrit on alertness." Lancet 19 (1980), pp. 846-848.

[150] Maarten E Witte, Lars BÃ $\tilde{s}_{s}$, Richard J Rodenburg, Jeroen A Belien, Rene Musters, Thierry Hazes, Liesbeth T Wintjes, Jan A Smeitink, Jeroen J G Geurts, Helga E De Vries, Paul van der Valk, and Jack van Horssen. "Enhanced number and activity of mitochondria in multiple sclerosis lesions." J Pathol 219 (2009), pp. 193-204.

[151] JR Wujek, C Bjartmar, E Richer, et al. "Axon loss in the spinal cord determines permanent neurological disability in an animal model of multiple sclerosis." J Neuropathol Exp Neurol 61 (2002), pp. 2332.

[152] Maulik S Zaveri, Amy Conger, Amber Salter, Teresa C Frohman, Steven L Galetta, Clyde E Markowitz, Dina A Jacobs, Gary R Cutter, Gui-Shuang Ying, Maureen G Maguire, Peter A Calabresi, Laura $\mathrm{J}$ Balcer, and Elliot M Frohman. "Retinal imaging by laser polarimetry and optical coherence tomography evidence of axonal degeneration in multiple sclerosis." Arch Neurol 65 (2008), pp. 924-928. 
[153] A. Z. Zeman, D. Kidd, B. N. McLean, M. A. Kelly, D. A. Francis, D. H. Miller, B. E. Kendall, P. Rudge, E. J. Thompson, and W. I. McDonald. "A study of oligoclonal band negative multiple sclerosis." $J$ Neurol Neurosurg Psychiatry 60 (1996), pp. 27-30. 